\title{
RESENHA
}

\section{A BNCC no contexto da contrarreforma da educação no Brasil}

Luiz Alberto Ribeiro Rodrigues ${ }^{1}$

AGUIAR, M. A. da S. e DOURADO, L. F. (Orgs). A BNCC na contramão do PNE 2014-2024: avaliação e perspectivas. [Livro Eletrônico]. Recife: ANPAE, 2018.

Esta obra, publicada pela Associação Nacional de Políticas e Administração da Educação (Anpae), reúne uma série de oito artigos produzidos por pesquisadores das áreas de política educacional e currículo, em que discutem o significado do processo que tem gerado a Base Nacional Comum Curricular (BNCC) e seus desdobramentos frente ao PNE 2014-2024.

São apresentados elementos que têm caracterizado a BNCC, construída em três distintas versões, sendo a primeira elaborada por especialistas no MEC e submetida a apreciação pública, recendo contribuições, em grande parte individualizada; a segunda versão, apresentada por componentes curriculares, foi discutida em seminários em todo o país, coordenados pela Undime e Consed. A terceira versão incorporou contribuições definidas por um grupo gestor instituído pelo MEC e excluiu a etapa do ensino médio.

Toda essa trajetória e as características que assumem cada versão deve ser compreendida a partir do contexto no qual a BNCC vem sendo instituída, ou seja, um tumultuado contexto político em torno da composição do governo central, na figura do presidente Michel Temer, após o impeachment da presidenta Dilma Rousseff, e que, a partir 2016 vem provocando um desmonte das conquistas democráticas e populares, sobretudo no que diz respeito aos avanços efetivados nas últimas décadas quanto ao direito à educação e às politicas educacionais. No âmbito educacional, posto em ação uma contrarreforma da Educação Básica, que impôs por meio de Medida Provisória, a reforma do ensino médio.

O contexto da contrarreforma da educação em curso apresenta-se bastante conservador e privatista, sobretudo porque veio acompanhada por um amplo processo de (des)regulação da educação, que favorece a expansão privada mercantil. Assim, questiona-se a ausência de um marco de referência, capaz de indicar princípios educacionais, concepções, utopias, sonhos, os desejados definidos coletivamente, no sentido de subsidiar as decisões em

\footnotetext{
1 Professor adjunto da Universidade de Pernambuco (UPE), Doutor em Educação pela UFPE, Membro do colegiado do Programa de Mestrado Profissional em Educação, Pesquisador em Política Educacional, membro do Grupo de Pesquisas Interdisciplinares em Formação de Professores, Politica e Gestão Educacional. E-mail: luiz.rodrigues@upe.br.
} 
torno da BNCC. Lembrou-se ainda que no Brasil documentos semelhantes já foram lançados, a exemplo dos "Guias Curriculares" nos anos 1980, os "Parâmetros Curriculares" nos anos 90 e as "Diretrizes Curriculares Nacionais" em 2001.

Contesta-se nesta obra a anseio da BNCC em fixar mínimos curriculares nacionais ou engessar a ação pedagógica com objetivos de aprendizagem dissociados do desenvolvimento integral do estudante. Argumenta-se que esta pretensão limita o direito a educação e a aprendizagem. Defende-se ao contrário, a garantia dos princípios constitucionais de liberdade de aprender, ensinar, pesquisar e divulgar o pensamento, a arte e o saber, bem como o pluralismo de ideias e de concepções pedagógicas.

Em defesa do currículo, põe-se em questão pressupostos que simplificam o debate pedagógico sobre o tema, tais como o vínculo imediato entre educação e desenvolvimento econômico, a redução da educação a níveis de aprendizagem, a restrição da crítica teórica à BNCC ao registro ideológico, a suposição de que os docentes não sabem o que fazer nas escolas sem uma orientação curricular comum. Além disso, sustenta esta obra, a BNCC fere o princípio de valorização das experiências extraescolares; afronta o princípio da gestão democrática das escolas públicas; atenta contra a organicidade da Educação Básica necessária à existência de um Sistema Nacional de Educação (SNE).

Rebatem os autores a pretensão de que, para garantir metas de aprendizagem, todas escolas precisam da mesma proposta curricular e da mesma orientação pedagógica. Em assim sendo, esconde-se a problemática da desigualdade social associada à educação, o fator investimento diferenciado na carreira do professor e nas condições de trabalho nas escolas, além do peso das condições de vida das famílias e das condições de estudo dos estudantes. Nesse sentido, defende-se que não é necessário que o currículo seja igual em todo país, até porque, na prática isso não seria possivel.

Ainda na linha do currículo, contesta os autores a auto determinação da Base como currículo prescrito e como norteador da avaliação. Afirma-se no debate, a ideia de que a BNCC resulta em uma listagem de competências, não podendo ser considerado currículo. Aponta-se, à luz de experiências nacionais e internacionais, a ausência de fatores fundamentais para o êxito de politicas desta natureza, tais como o formato de intervenção descentralizada via currículos, a valorização dos professores, o financiamento inadequado para a educação.

Foi identificada ainda que no bojo de seu conteúdo, falta à BNCC a articulação referente à concepção e diretrizes da Educação Básica, tendo em vista a construção de uma educação formadora do ser humano, cidadão, capaz de influir nos rumos políticos e econômicos do país, capaz de criar novos conhecimentos, de criar novas direções para o nosso futuro comum.

Em meio a esse momento de crise da politica brasileira, ganham força na definição de políticas curriculares que estabeleceu o último formato da BNCC, algumas organizações privadas, assumindo um papel condutor e indutor de sua aprovação e disseminação. Realce para a Fundação Lemann 
associada ao Cenpec, Instituto Natura, Instituto Ayrton Senna, Instituto Unibanco, Fundação SM, Insper e Instituto Fernando Henrique Cardoso.

Os autores analisam esse contexto e apontam para a existência de uma nova configuração de poder que se vai se afirmando no âmbito do MEC e a consequente alteração na correlação de forças do $\mathrm{CNE}$, na perspectiva de fortalecer politicas que, no limite, apresentam um forte viés privatista favorecendo interesses do mercado.

Ressalta esta obra que as politicas materializam-se em estratégias de privatização e incidem em três dimensões estratégicas, didaticamente consideradas em separado: oferta educativa; gestão educacional e sobre o currículo.

Alerta-se ainda para outros passos que poderão ocorrer em decorrência da BNCC, entre as quais a avaliação em larga escala, que terminam por legitimar determinados saberes e ampliar ainda mais a seletividade da educação, prejudicando grupos sociais menos favorecidos e elevando a desigualdade educacional.

Mas afinal, o que tem justificado então a BNCC? No contexto desta obra há indicações de que os interesses imediatos do mercado pautam a possível criação de um mercado para livros didáticos, ambientes instrucionais informatizados, cursos para capacitação de professores, consultorias na formulação dos "currículos em ação" nos municípios; seminários envolvendo instituições estrangeiras com vistas à formação de professores; movimentos das diversas fundações no sentido de produção de material e capacitação.

Interessante crítica nesta obra sobre o significado que ganha a BNCC, como um artificio que pode ser chamado de "apostilagem dos processos pedagógicos", ou seja, os problemas da educação são apropriados por fundações privadas, inúmeras delas ligadas a bancos, e são dadas soluções que entendem ser as 'indispensáveis', porque "mais rápidas e mais fáceis". Recorda o texto que essas fundações têm sido buscadas por gestores públicos, em nivel estadual e municipal, com objetivos de indicar aos professores como devem atuar, a partir de periodos curtos de formação, com a criação de material didático que devem seguir à risca - o que dar em que dia, em que hora, ou seja, verdadeiras "apostilas" - e com um controle do que fazem em sala de aula.

Lembra os autores tratar-se de uma falsa aí inclusa, pensar que tudo estará resolvido, se os docentes forem obedientes, aplicando em seus estudantes estas fórmulas mágicas. Como ocorrem em outros países, esse tipo de intervenção não tem dado certo, não considera a realidade complexa onde a escola se encontra. Tendem ser portanto, soluções insuficientes e a culpa voltará aos docentes, por "não executarem" o processo indicado e ainda reforça um discurso culpabilizando-se as universidades pela má formação dada aos docentes.

Também se reconhece que, apesar dos equívocos quanto a tentativa de imposição da BNCC como um currículo, de sua vinculação à processos de avaliação em larga escala, ao mercado de livros e material didático, há um contraponto a ser considerado: a autonomia na gestão pedagógica, garantida 
aos sistemas de ensino, nos estados e município, e materializada nos projetos políticos pedagógicos (PPP).

Além disso, recordam os autores de processos de resistências observados neste período histórico, em que surgiram movimentos com ideias que mobilizam estudantes e seus docentes em torno do que significam e como devem ser as escolas que querem e que estão dispostos a fazer funcionar porque atendem às suas necessidades. Nesse sentido são mencionados a força de resistência expressa em movimentos, como os "Ocupa", que foi sendo produzido nas salas de aulas, por seus docentes e discentes nestes últimos anos. Ressalta esta obra, não é possivel quebrar os sonhos de milhares de docentes e de milhões de estudantes por escolas melhores dos quais eles são muito bons conhecedores.

Expressam ainda os autores a necessidade de reconhecer, nas realidades cotidianas, mais práticas educativas do que as de obediência subserviente às normas autoritárias. Assim, expressam a necessidade de reconhecer que não estivemos e não estamos parados, que a luta pela escola pública e por propostas curriculares respeitosas com os sujeitos da escola e plurais epistemológica e culturalmente, vale a pena e já está em andamento.

A contribuição de reconhecidos pesquisadores na área, tais como seus organizadores somados aos demais autores, Alice Casimiro Lopes; Elizabeth Macedo; Erasto Fortes Mendonça; João Ferreira de Oliveira; Inês Barbosa de Oliveira; Nilda Alves; Theresa Adrião e Vera Peroni, faz dessa obra um registro crítico necessário para construir horizontes de superação dos limites em que foram impostos a atual política educacional no Brasil. Trata-se portando de uma obra recomendada aos educadores e pesquisadores da educação que buscam examinar a politica da educação no Brasil e reconstruir os novos rumos para uma formação cidadã, a partir de uma educação pública e de qualidade social referenciada. 